\title{
Canine Degenerative Lumbosacral Stenosis: Prevalence, Impact And Management Strategies
}

This article was published in the following Dove Press journal:

Veterinary Medicine: Research and Reports

\section{Andrew Worth (iD) \\ Björn Meij ${ }^{2}$ \\ Nicholas Jeffery ${ }^{3}$}

'Massey University Veterinary Teaching Hospital, School of Veterinary Science, Massey University, Palmerston North 4442, New Zealand; ${ }^{2}$ Department of Clinical Sciences of Companion Animals, Faculty of Veterinary Medicine, Utrecht University, Utrecht 3508 TD, The Netherlands; ${ }^{3}$ Texas A\&M Veterinary Medical Teaching Hospital, College Station, TX 77845, USA
Correspondence: Andrew Worth Massey University Veterinary Teaching Hospital, School of Veterinary Science, Massey University, Palmerston North 4442, New Zealand

Tel +6463505329

Email a.j.worth@massey.ac.nz

\begin{abstract}
Canine degenerative lumbosacral stenosis (DLSS) is a syndrome of low back pain with or without neurologic dysfunction associated with compression of the cauda equina. Most commonly occurring in medium- to large-breed dogs of middle to older age, German shepherd and working dogs are predisposed. Diagnosis is based on a combination of clinical signs, advanced imaging and ruling out other differential diagnoses. The volume of the intervertebral foramina at the lumbosacral junction is naturally reduced on extension but degenerative changes lead to a more marked reduction that can impinge the $L 7$ nerve roots Evidence is lacking on which to base decision-making for treatment of dogs with DLSS. However, surgical intervention may be indicated in dogs that do not respond to conservative management, or for dogs in which there is a requirement to work that prevents lifestyle adjustments. Improvements in electrodiagnosis and novel intra-discal treatments may improve the management of DLSS in the future.
\end{abstract}

Keywords: lumbosacral, cauda equina, review, degenerative stenosis, low back pain

\section{Introduction}

Canine degenerative lumbosacral stenosis (DLSS) describes a syndrome in dogs associated with degeneration of the structures of the lumbosacral junction leading to signs of low back pain \pm neurologic dysfunction associated with compression of the cauda equina. DLSS has a multifactorial origin in which intervertebral disc (IVD) degeneration plays a major role. However, the DLSS syndrome lacks pathognomonic characteristics, and diagnosis is often presumptive based on a combination of clinical signs, findings on advanced imaging, and ruling out other specific etiologies that cause cauda equina compression.

In 1989 Chamber first used the descriptive term "degenerative lumbosacral stenosis" to refer to a syndrome of acquired narrowing of the vertebral canal, intervertebral foramina, or both, resulting in a compressive radiculopathy of the cauda equina. ${ }^{1,2}$ Loss of hydration of the nucleus pulposus and degeneration leads to bulging of the annulus fibrosus of the L7-S1 intervertebral disc (a type II protrusion) and loss of intervertebral spacing. One or more nerve roots of the cauda equina may become compressed by a combination of disc prolapse and hypertrophy/fibrosis/osteophytosis of the supporting tissues associated with the L7-S1 articulations (Chambers 1989, Godde and Steffen 2007). 1,3 The degenerative changes and pre-disposing anatomical anomalies that are associated with DLSS are summarized in Box 1.

DLSS is most common in medium to large dogs of middle to older age. ${ }^{4,5}$ There is a breed predisposition in the German shepherd dog (GSD), a breed commonly 
Box I Pathology Recognised As A Component Of Degenerative Lumbosacral Stenosis In Dogs (modified from Worth et al 2009)

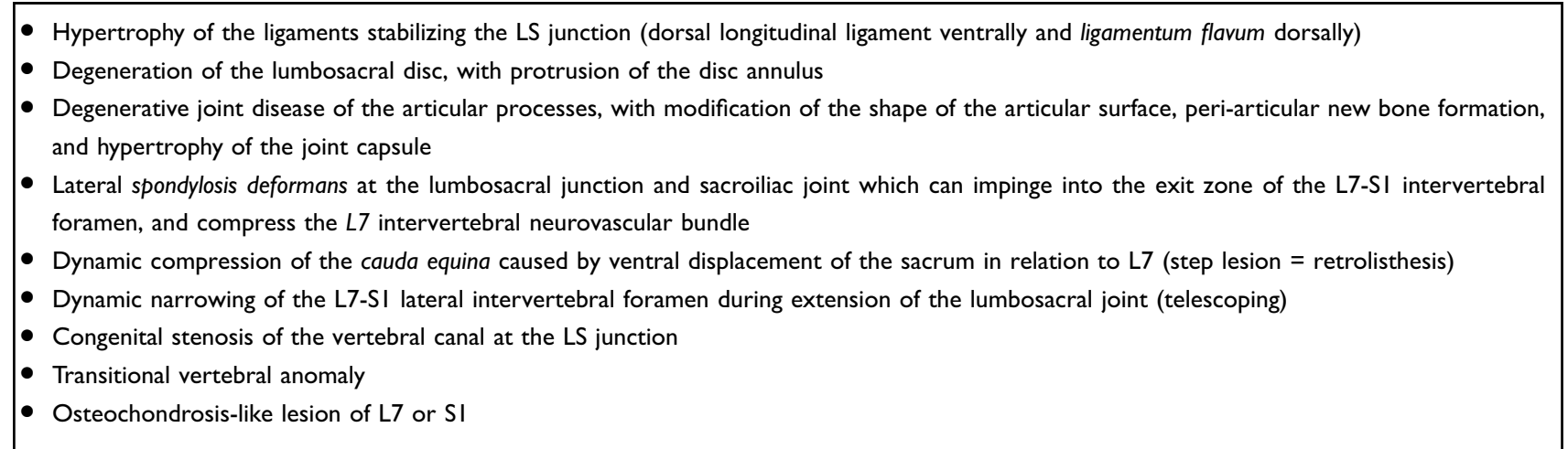

used as a working dog by Police and Military organizations worldwide. The Belgian Malinois, even more popular as a working dog in the US Military Working Dog program, also develops DLSS but at a lower incidence than GSDs under the same conditions. ${ }^{6}$ It is likely that work-related stress as well as breed predisposition plays a role in DLSS.

There is currently no consensus on treatment selection for dogs with DLSS and outcome data based on high-quality evidence with which to compare proposed interventions is lacking. ${ }^{7}$ Management of DLSS in mildly affected dogs is typically conservative, using analgesic and anti-inflammatory drugs and change in lifestyle to avoid exacerbation of clinical signs. Epidural steroid injections have been used for dogs with minimal neurological deficits but may not be effective in the longer term. ${ }^{8}$ Intradiscal injections are under investigation in a subcategory of patients with low back pain and minimal compression of neural tissue but efficacy still needs to be demonstrated. ${ }^{9-11}$ Strengthening the core muscles in a dog with DLSS is also promoted as an effective treatment and physical rehabilitation methods warrant more investigation.

Surgical intervention may be indicated in dogs that do not respond to conservative management, or for dogs in which there is a requirement to work that prevents lifestyle adjustments. However, with the current lack of objective measures of lost function or unbiased comparative studies, there is no evidence on which to base a decision to elect surgical intervention over conservative management. This conclusion has also been reached regarding the role of surgery in the management of human low back pain.

\section{Pathogenesis Of DLSS}

Normally, limits to vertebral motion are determined by both passive and active components, which afford a highly mobile neutral zone of physiological motion, and a low motion zone of high resistance (restricted elastic zone). The vertebral bodies, intervening intervertebral discs, the longitudinal ligaments, ligamentum flavum and the articular processes with their joint capsules all provide passive stabilization to the spinal column. Whereas the epaxial and hypaxial paravertebral muscles are the active stabilizers of the lumbosacral motion segment and coordinate their activity through proprioceptive input. ${ }^{12}$ The active stabilizers are augmented by abdominal musculature.

The degenerative process that leads to DLSS is thought to start in the LS intervertebral disc, potentially as the result of prolonged or excessive strain of the LS junction beyond the normal limits of physiologic function. ${ }^{13}$ In a cohort of police GSDs, radiographic progression of degeneration (progressive spondylosis deformans, a narrowing of the lumbosacral intervertebral space, misalignment of the lumbosacral canal, and increasing mineralization of L7-S1 discs) was noted over a 3year period. ${ }^{14}$ As the disc degenerates it becomes stiffer as the concentration of proteoglycan and water in both the annulus fibrosus and nucleus pulposus falls. ${ }^{13}$ The eventual outcome is fibroid metaplasia, although a recent study suggests that also in non-chondrodystrophic dogs, like in chondrodystrophic dogs, chondroid (and not fibroid) metaplasia should be used to describe the tissue changes in the IVD. ${ }^{15}$ Tearing in the weakened annulus results in protrusion of nuclear material (Hansen Type II disc prolapse) or rarely, complete extrusion of the nucleus pulposus through the annulus [Hansen Type I disc prolapse]. ${ }^{16}$ Tearing of Sharpey's fibers at the annular margin due to the failure of the degenerating annulus to absorb and distribute loading, results in the formation of enthesiophytes. As the intervertebral disc degenerates, the intervertebral spacing narrows resulting in protrusion of the annulus fibrosus and reduction in the volume of the lateral intervertebral foramina. ${ }^{1}$ The lateral L7-S1 intervertebral neurovascular 
foramen is not a simple aperture but rather a tunnel, having an entrance, middle and exit zone through which the $L 7$ nerve root transit from the vertebral canal to the periphery. ${ }^{3,17}$ The L7 nerve roots lie abaxially within the lateral recess of the vertebral canal of L7, having exited the dural sac at the level of the L6 vertebral body. ${ }^{18}$ The $L 7$ nerve roots pass from the lateral recess to the intervertebral foramen rostral to the intervertebral disc via a dorsolateral notch in the caudal aspect of the dorsal body of L7. Therefore, unless very large and very lateralized, a protruded disc will place pressure on the rest of the cauda equina dorsally but will spare the L7 nerve roots. Additionally, as the vertebral spacing is lost, telescoping of the sacral articular processes into the intervertebral neurovascular foramina occurs on extension leading to dynamic L7 impingement at the exit zone (Worth et al 2017a). ${ }^{19}$

The extent to which anatomical alteration occurs affects the type and severity of the clinical signs detected. Lateral (foraminal) compression of the L7 or S1 nerve roots and their blood supply leads to pelvic limb signs: repetitive flexion of a pelvic limb, pain elicited on pelvic limb extension/lordosis testing, intermittent to progressively worsening lameness induced by exercise, and sciatic nerve deficits in severe cases. ${ }^{1,2}$ Compression of the exit and middle zones was a common $(65 \%)$ feature of DLSS in one study. ${ }^{3}$

The origin of low back pain in dogs with DLSS has been typically attributed either to direct nerve compression associated with inflammation (including the basivertebral nerve that innervates the vertebral bodies) or damage to neighboring soft tissue structures, including the annulus fibrosus, ligamentum flavum, dorsal longitudinal ligament and synovial membrane. DLSS is considered capable of inducing neuropathic pain, ${ }^{20}$ and its clinical relevance is supported by overexpression of calcium channel (receptor) subunit alpha-2-delta, ${ }^{21}$ substance $\mathrm{P}^{22}$ and calcitonin gene-related peptide, ${ }^{23}$ in dorsal root ganglion of dogs with DLSS. Also the clinical response of dogs with low back pain on gabapentinoid molecules that modulate the calcium channel (receptor) subunit alpha-2delta supports the role of neuropathic pain in DLSS. ${ }^{24}$

In recent years, there have been new insights into the origin of low back pain in dogs with DLSS.

-MRI in dogs with low back pain may show early degeneration of the intervertebral disc without evident compression of the cauda equina.

-Discogenic pain can cause human low back pain: the diagnosis is made by intradiscal injection of a small volume of saline solution and assessing the evoked pain response in the awake patient.
-Profiles of inflammatory cytokines and chemokines are related to intervertebral disc degeneration in dogs. Prostaglandin E2 (PGE2), a pain mediator, is significantly increased in degenerated discs, even at early stages. ${ }^{25}$

-Experimental dogs with induced IVDD and canine patients with low back pain due to spontaneous IVDD that were treated by intradiscal injection with slow-release platforms (hydrogels and microspheres) with an NSAID (celecoxib) showed improvement on a biochemical, imaging, histological and clinical level. ${ }^{9}$

In conclusion, there seems to be a role for more focal administration of anti-inflammatory drugs in the vicinity of ligamentous, neural and disc tissue to address the inflammatory component and thereby reduce the pain. Clinical and imaging stratification plays a crucial role in deciding which patients can be treated first by conservative management, by oral medication or more focal medical administration and which are better suited to surgical management. Currently, this stratification is problematic due to lack of objective analysis.

\section{Prevalence}

DLSS is reported to be more prevalent in large-breed and active or working dogs [Police, military or sporting dogs] and especially the GSD and retriever breeds. ${ }^{1,4,26,27}$ Affected dogs are typically mature and $>25 \mathrm{~kg}$ bodyweight. In the two largest studies to date, the mean age at first diagnosis/treatment was 5.5 and 5.8 years. ${ }^{4,5}$ Males appear to be over-represented, with a male: female ratio of $>1.7: 1$ in studies of predominantly non-working dogs with less gender bias than would be found in working dog populations. ${ }^{4,5}$

Insurance data for dogs with veterinary health-care and life insurance coverage ( $n=665,249$ and 552,120, respectively) of one pet insurance company in Sweden (Agria, 1995-2006) revealed diagnosis of lumbosacral IVD herniation and DLSS in 1,574 of dogs, with an overall incidence rate of $5.6(95 \% \mathrm{CI}$, 5.4 to 5.9 ) occurrences/10,000 dog years at risk (DYAR). ${ }^{28}$ The male-to-female ratio was 1.5:1. The 8 breeds at highest risk were all non-chondrodystrophic, and German shepherd dogs were over-represented. German shepherd dogs had the highest risk of lumbosacral IVD degeneration-related disease in this study and had a 7\% lifetime prevalence of any IVD degeneration-related disease before the age of 12 years.

\section{Impact Of DLSS}

Other studies have also noted the high prevalence of spinal disease in the dogs used most frequently by military and police forces for security, patrol, and detection duties, although the specific reasons for the high risk are currently 
unknown. 6,29 Unfortunately, the terms "spinal cord disease" and "spinal disease" used in such studies include diseases other than DLSS specifically. Overall 27\% of police dogs in a New Zealand study were retired or euthanized due to back and/or spinal problems, and a high proportion of these were believed to have involved the lumbosacral joint. ${ }^{29}$ The average age of loss (natural or unnatural death) or retirement from active duty was 6.6 years and planned retirement ( 8 years) was only reached by $40 \%$ of dogs; inability to cope with the physical demands of the job (65\%) was the most common reported reason. $^{29}$

\section{Predisposing Factors In The Development Of DLSS}

Working dogs are often trained to scale walls or search by standing on their pelvic limbs and to bite and hold a person by the arm, all activities that require maximal LS flexion. Repetitive strain at the extent of the range of motion may stress the LS junction, leading to degeneration of the LS intervertebral disc. Additionally, in GSDs, there is an increased prevalence of congenital anomalies that can predispose affected dogs to DLSS. A separated osteochondral lesion of the dorsal endplate of S1 (or more rarely L7) that histologically resembles osteochondrosis has been reported in the GSD. $^{30-32}$ Ondreka et al (2013) reported a 10\% incidence of sacral osteochondrosis in GSDs compared to $\sim 6 \%$ in nonGSDs and found a moderate heritability of 0.5 in GSDs. ${ }^{33}$ The osteochondral bodies can protrude into the vertebral canal or the lateral recess of $\mathrm{L} 7$ with resultant nerve root compression. Despite removing the osteochondral lesion, surgical damage to the dorsal annulus and loss of the normal architecture of the vertebral end-plate can predispose to degeneration of the L7-S1 disc that can necessitate LS stabilization. ${ }^{34}$

Lumbosacral transitional vertebral (LTV) anomalies are congenital deformities due to abnormal differentiation of the LS junction in utero ${ }^{35}$ and are more prevalent in GSDs than in other breeds. ${ }^{33,36}$ The prevalence of LTV in the GSDs is reported to range from $3.5 \%$ to $29 \%$, with the large variation likely due to distinct gene pools in different countries and whether very mild phenotypes are included in the definition (e.g. segmentation of the sacral vertebral spinous processes). Dogs with LTV are reported to have a higher risk of developing cauda equina syndrome, ${ }^{36-39}$ potentially as the result of abnormal rotational forces induced by the malarticulation and malalignment present of the LS junction.
The GSD may also be predisposed to DLSS due to a comparatively restricted vertebral canal height at the lumbosacral junction compared to other breeds. ${ }^{33}$ There was also a more distinct difference in the vertebral canal height measured at the caudal aspect of L7 compared to that of the cranial aspect of the sacrum.

In humans, the displacement of L5 anterior to the sacrum (degenerative spondylolisthesis) is associated with lumbar pain. In some dogs with DLSS, retrolisthesis (ventral displacement of the sacrum relative to L7) is noted radiographically, but this "step lesion" is an inconsistent feature in dogs with DLSS in most studies and has been shown to have no correlation with the development of clinical signs of DLSS. ${ }^{14,40}$ Ventral displacement of the sacrum with malalignment between the caudal vertebral canal of L 7 and the cranial sacral canal has been reported in $\sim 70 \%$ of dogs with DLSS. ${ }^{41}$ However, this "step-lesion" is also seen in healthy dogs free of clinical signs of DLSS, ${ }^{2,42}$ although at lower prevalence. ${ }^{33}$ Although it might be anticipated that the step would be associated with a greater motion of this segment, measurements of ventral displacement do not support this viewpoint. Nevertheless, a greater absolute distance of step was a feature of dogs with DLSS compared to normal age/weight-matched dogs. $^{43}$ The clinical relevance of the cranial margin of the dorsal lamina of $\mathrm{S} 1$ and the role of telescoping remains a point of discussion. Although its measurement on radiographs is reliable, ${ }^{44}$ the rostral projection of the sacral lamina may not be a predisposing factor in the development of cauda equina syndrome due to DLSS in GSD. ${ }^{45}$

\section{Lateral Intervertebral Foramen Narrowing And Nerve Root Compression}

In dogs with DLSS managed surgically narrowing of the L7$\mathrm{S} 1$ lateral intervertebral foramina has been associated with a poor long-term prognosis. ${ }^{46}$ Radiographs do not allow accurate evaluation of intervertebral foraminal dimensions due to the superimposition of the articular processes of L7 and S1, particularly in patients with degenerative changes. In dogs with clinical signs of DLSS (pelvic limb lameness and/or lumbosacral pain), there was a negative linear relationship between the angle of the LS junction and intervertebral foraminal area on CT, such that L7-S1 intervertebral foraminal area decreased as extension increased. Yet there was no such relationship in control dogs, unaffected by DLSS. ${ }^{47}$ The measurements were made in sagittal orientation, whereas true foraminal area would be perpendicular to the path of the $L 7$ 
roots as they course through the entrance, middle and exit zones, potentially affecting the accuracy of these observations. Measurement of the lateral intervertebral foramen using CT volumetric reconstruction can be used to demonstrate dynamic changes present during range of motion, Figure 1. Positioning the LS junction in full extension decreases the volume of the lumbosacral IVF. ${ }^{19}$ Dynamic narrowing was more pronounced in GSDs with signs of DLSS than in GSDs not overtly affected by DLSS.

\section{Principles Of Diagnosis Of DLSS}

The term "cauda equina syndrome" relates to the clinical signs caused by a lesion involving the nerve roots of the cauda equina, or affecting the L5-L7, sacral or caudal vertebrae, or their associated soft tissues that results in cauda equina compression. ${ }^{48}$ DLSS is but one of the differential diagnoses for cauda equina syndrome. Clinical signs of cauda equina disease include pelvic limb lameness, pain and disorders of continence and tail movement. Cauda equina syndrome can be caused by neoplasia, discospondylitis, epidural empyema, tethered cord syndrome, epidural lipomatosis, and epidural/para synovial cysts in addition to DLSS. $^{49-53}$ These differentials must be ruled in or out by diagnostic investigations. ${ }^{48,54}$

A diagnosis of DLSS in a dog should be based on the identification of dysfunction associated with the cauda equina and/or the presence of pain that is inducible by motion or manipulation of the LS junction, combined with supportive advanced imaging findings and having excluded alternative differential diagnoses. Having a high index of suspicion for this condition and using appropriate manipulative tests have been highlighted in order to improve the identification of dogs with DLSS. ${ }^{1,26}$

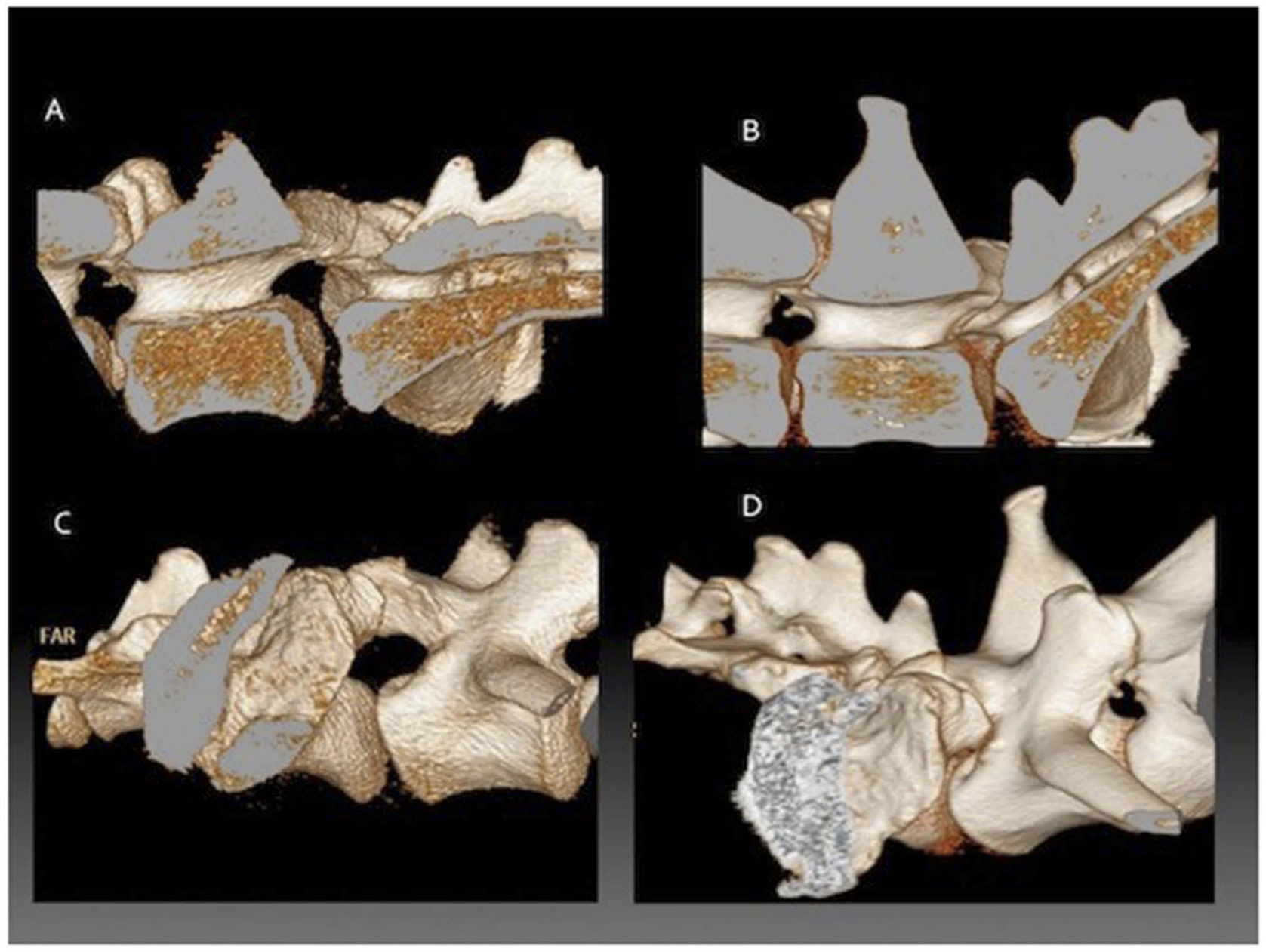

Figure I Three-dimensional reconstructions from CT data showing the lumbosacral junction of a German shepherd dog during flexion compared to extension. The vertebral column has been sectioned in the midline to only include the right half. (A) external detail of the LS junction in flexion, (B) internal detail of the LS junction in flexion, (C) external detail of the LS junction in extension, (D) external detail of the LS junction in extension. 
Currently, the vast majority of suspected cases of DLSS do not present with neurological deficits and, instead, present solely for low back pain. Dogs with low back pain present with reluctance to jump and/or are slow to rise, with or without overt pain during these activities. Even in dogs with neurological signs there is paresis but ataxia is uncommon; only severely affected individuals will show depression in toe knuckling response.

\section{Clinical Signs}

Reluctance to jump, or evidence of pain when jumping or when rising from a prone position, or when climbing stairs ( $\sim 90 \%$ ), and purported evidence of pain or stiffness during physical activity $(\sim 90 \%)$ are most frequently cited by owners. ${ }^{4}$ Isolating hyperaesthesia to the LS junction (the dog vocalizes or resists examination in response to dorsal digital pressure or LS junction manipulation) is an important clinical sign of DLSS. Hyperaesthesia/avoidance during extension or induced by direct digital palpation have been consistently reported in $90+\%$ dogs affected by DLSS. ${ }^{40}$

In some human patients with lumbosacral degeneration, low back pain can worsen when exercising then subside following rest. The proposed mechanism is temporary ischemia (termed "intermittent claudication") caused by exercise-induced pressure on the vascular supply of the L5 nerve roots as the LS junction extends. ${ }^{1}$ Intermittent pelvic limb lameness associated with activity is reported in some dogs with DLSS and may be induced by the same mechanism. ${ }^{5,26,27}$ Affected dogs may appear sound at the walk and trot, but will hold a pelvic limb flexed and be briefly only partly-weight bearing immediately after jumping a wall or jumping into a high vehicle.

\section{Physical Examination}

To increase the likelihood of detecting low back pain at the LS junction in dogs, physical examination should include direct digital pressure over the lumbosacral space with and without extension of the hips; and the "lordosis" and pelvic tilt tests. ${ }^{1,54}$ Though previously reported as useful, the authors find the tail jack test to be ambiguous as it evokes a response in many randomly tested normal dogs. Hyperaesthesia on dorsal LS junction pressure, avoidance behavior, vocalization or an aggressive reaction on manipulation are all putative indications of low back pain in dogs with LS disease. Because these signs also occur with diseases of the coxo-femoral joint or low lumbar vertebrae, signs of pain elicited on extension of the hip are not specific for lumbosacral disease. Pain on rotation or abduction of the hip (without extension or LS pressure) is more specific for coxo-femoral joint disease than LS disease. Therefore, pain induced by hip extension without pain on abduction or rotation of the hip is more supportive of low back pain. Given that many large dogs have both hip dysplasia and DLSS the clinician has to determine the most clinically relevant condition in order to appropriately treat each individual. The initial extension of the hip joints (one at a time) with the dog standing or in lateral recumbency should not cause pain unless the dog has pain derived from the hip. However, many dogs with DLSS and hip dysplasia allow gradual extension of the hip joints but start to show a pain reaction when hyperextending the lumbosacral junction. Especially in these cases, the experienced clinician will note the difference between a mild response to extension of the dysplastic/arthritic hip joint and the overt pain response due to added stress on the lumbosacral junction. This is evidence of the dynamic nature of the compression and stenosis that worsens with extension. The pelvic tilt test is the most specific test for localization of pain on manipulation to the LS junction. The examiner places one hand between the dog's thighs to cradle the pubis and the other hand is placed dorsally over the LS junction, to induce extension (lordosis) of the LS junction.

Overt neurological deficits are extremely rare in DLSS patients. Textbooks often state that urinary incontinence is part of the clinical syndrome but it is more likely to be a concomitant problem than the direct result of cauda equina compression. Spinal nerves comprising the cauda equina are much more resilient to compression than the spinal cord itself, and experimental studies have shown that the cauda equina in dogs can withstand considerable compression without suffering nerve fiber damage. Hence, it is important that dogs with DLSS showing ataxia and/or proprioceptive deficits are thoroughly investigated to exclude other conditions, such as degenerative myelopathy, thoracolumbar IVD herniation, discospondylitis, or neoplasia.

In more chronic cases, a depressed withdrawal, peroneal or cranial tibial myotatic reflex may be present on neurological examination. The patellar reflex should be normal but may appear exaggerated due to hypotonia of the flexor muscles of the stifle that normally antagonize the quadriceps muscles "pseudo-hyperreflexia". ${ }^{1,48}$ A clinician should endeavor not to confuse pseudo-hyperreflexia (a lesion at L7-S1) with an upper motor neuron lesion rostral to the pelvic limbs (T3-L3 lesion)

\section{Diagnostic Imaging}

In a dog with low back pain, plain radiographs of the lumbosacral region are primarily used to rule out boneassociated neoplasia, discospondylitis, lesions from 
trauma, and vertebral anomalies. ${ }^{48}$ Correct positioning is important and was illustrated in a previous review. ${ }^{55}$ Signs consistent with DLSS on plain radiographs may include narrowing of the intervertebral disc space, ventral or lateral spondylosis, end-plate sclerosis of caudal L7 and cranial S1, and ventral displacement of the sacrum at the LS junction. ${ }^{43}$ Spondylosis/spondylarthrosis and sclerosis of the endplates of L7 and/or S1 also increase in prevalence with age. The presence of a vacuum phenomenon (a gas radiolucency within the lumbosacral disc) has been reported in dogs with DLSS following positioning for radiography with the pelvic limbs extended. ${ }^{56,57}$ The vacuum phenomenon is a well-recognized radiological sign of degenerative disc disease in humans.

However, plain radiography has poor accuracy due to an inability to image soft-tissue structures (false-negative diagnoses) and because degenerative changes can be present without clinical signs (false-positives). ${ }^{37}$ In a cohort study of working GSDs plain radiographic findings were not found to be predictive of the development of DLSS. ${ }^{14}$

Though widely used in the past, advanced imaging methodologies have superseded contrast radiography: myelography, discography, epidurography. ${ }^{2,58}$

Computed tomography [CT] is advantageous over radiography because it provides superior resolution of soft tissue and provides transverse (axial) image orientation. ${ }^{59}$ Modern multi-slice, helical CT scanners can rapidly generate highresolution volume datasets and have improved the ability to reconstruct the image in three dimensions, with reduced artifact from volume-averaging. CT imaging allows evaluation of the lateral recesses of the L7 vertebra, the entrance, middle and exit zones of the intervertebral foramina, articular process pathology, and the extent of prolapse of the dorsal annulus. ${ }^{59}$ If the dog is not positioned with the LS junction in extension, then the dynamic component of disc protrusion and telescoping of S1 will be overlooked.

Dogs with clinical signs of DLSS typically show loss of epidural fat around nerve roots, increased soft tissue opacity effacing the intervertebral foramina, bulging of the annulus fibrosus, spondylosis impinging the foramina, displacement of the dural sac, a smaller L7-S1 lateral intervertebral neurovascular foramen, a narrowed LS vertebral canal, thickening of the articular processes, and osteophytosis of articular processes on CT images. ${ }^{60,61}$

The extent to which the L7-S1 disc bulges dorsally as a proportion of the dorso-ventral dimension of the vertebral canal is an average $27 \%(20-43 \%)$ in normal Hound dogs, ${ }^{18}$ and care must be taken not to over-interpret the degree of disc protrusion on CT in dogs. ${ }^{62}$

Altering the degree of extension/flexion of the LS junction during imaging demonstrates dynamic alterations in the dimensions of the lateral L7-S1 intervertebral neurovascular foramen and dorsal intervertebral canal. ${ }^{60}$ This dynamic foraminal narrowing has been confirmed using CT volumetric analysis, ${ }^{19}$ a method that was later shown to be repeatable. ${ }^{63}$ Moving the LS junction from a flexed to an extended position reduced the mean foraminal volume by $74 \%$ in greyhounds, $79 \%$ in GSDs without DLSS and $85 \%$ in GSDs diagnosed with DLSS. In the extended LS position, the foraminal volumes were smaller in GSDs diagnosed with DLSS than in GSDs without clinical signs of DLSS. ${ }^{19}$

Magnetic resonance imaging (MRI) is the most sensitive imaging modality for the detection of degeneration of the nucleus pulposus. Dehydration of the nucleus pulposus is seen as loss of the normal bright signal in T2-weighted images. ${ }^{3,64}$ Additionally, prolapse of the disc annulus and attenuation of the normal epidural fat signal, which can indicate nerve root compression at the level of the foramina, is more readily demonstrated with MRI than CT and affects up to $68 \%$ of dogs with DLSS., 365,66

Meticulous positioning of the animal and a 1-2 $\mathrm{mm}$ slice protocol are important to avoid partial-volume artifacts and false-positive findings when imaging the foramina with MRI as side to side comparison is a critical step in evaluation. ${ }^{3}$ The dog should be positioned in dorsal recumbency with the lumbosacral junction in extension via positioning troughs and sandbags to maximize diagnostic sensitivity. ${ }^{67}$ Rotation around the vertebral axis must be avoided and the dog should be orientated in the scanner gantry such that the vertebral column is parallel to the table in the longitudinal plane.

\section{Relationship Between Imaging Findings And Response To Therapy}

There is no consensus of opinion on what constitutes an advanced imaging diagnosis of DLSS and validation of imaging findings is hampered by lack of a defined disease definition. When attempting to predict the outcome for any dog affected with DLSS, the results of imaging may be less important than the clinical signs and surgical factors. A significant association between imaging studies and postoperative outcome was not found in 12 working dogs treated surgically for DLSS, ${ }^{68}$ although the study had low statistical power. Similarly, in a cohort of $27 \mathrm{dogs}$ with DLSS, no correlation was found between the degree of 
cauda equina compression on MRI and the severity of the clinical signs. ${ }^{66}$ However, the dogs were imaged in a neutral (frog-leg pelvis) rather than extended lumbosacral joint position, which may have reduced the degree of cauda equina compression identified if DLSS is a dynamic disease. A substantial agreement has been shown between $\mathrm{CT}$ findings and MRI findings with regard to the position of the dural sac, the location of disc protrusion, the degree of disc protrusion, the amount of swelling of spinal nerve roots and the amount of epidural fat. ${ }^{41}$ However, the extent of agreement between the findings at surgery and CT or MRI with regard to the degree and location of disc protrusion and swelling of spinal nerve roots was only moderate. Dogs with severe disc protrusion were 6.5 times more likely, and dogs with a lumbosacral step were 1.8 times more likely to have ongoing clinical signs and fail to improve after surgery in a later study. ${ }^{5}$

CT volumetric measurement of foraminal volume was shown to correlate with clinical signs in a cohort of GSD Police Dogs. A foraminal volume of $<90 \mathrm{~mm}^{3}$ as measured from CT in LS extension differentiated most of the DLSS affected dogs from the unaffected dogs in a recent study in which the positive predictive value of a foraminal volume $<90 \mathrm{~mm}^{3}$ was $75 \%$. The negative predictive value of a foraminal volume $>90 \mathrm{~mm}^{3}$ was $86 \%{ }^{19}$

\section{Electrodiagnostics}

Though infrequently performed, electrodiagnostic investigations are potentially a better indicator of lesions/compression of the cauda equina than imaging. In relatively severe cases, fibrillation potentials and positive sharp waves can be detected in many of the pelvic limb or tail base (sacrocaudalis dorsalis) muscles. ${ }^{69}$ Similarly, spinal somatosensory-evoked potentials are reduced in amplitude and elongated in latency in dogs diagnosed with DLSS. ${ }^{70}$ Data have also been assembled to suggest that the F-wave latencies may be most sensitive for the detection of L7 nerve compression associated with DLSS. ${ }^{71}$ Further investigations are required to determine what test(s) is reliable enough or constitute evidence supportive of the diagnosis. Currently, imaging is often used as the gold standard preoperative diagnostic test, meaning that there is a limit to the currently assigned diagnostic capabilities of electrodiagnostics. It is possible that electrodiagnostic diagnosis may constitute a superior gold standard.

\section{Management Strategies}

Both surgical and conservative medical management have been advocated for DLSS, but there are no properly conducted clinical trials upon which to form an evidencebased treatment recommendation. ${ }^{7}$ Conservative management involves reducing the dog's activity and prescribing anti-inflammatory medication and is recommended as the initial therapy for those dogs with DLSS that present with pain only, and whose owners are willing to modify their dog's lifestyle to avoid strenuous exercise. ${ }^{1}$ Both non-steroidal anti-inflammatory drugs (NSAIDs) and corticosteroids can provide effective temporary pain relief, although clinical signs may return with the discontinuation of medical therapy. ${ }^{72}$ Of 16 dogs treated conservatively with 8 to 10 weeks' rest and NSAIDs, only $50 \%$ of owners reported a good outcome and $25 \%$ of the dogs suffered relapse within the study period. ${ }^{26}$ Others have noted that the majority of surgical candidates in retrospective studies failed conservative management prior to surgical treatment. ${ }^{3,62}$ Most recently De Decker and co-authors reported that 17/31 dogs with DLSS (55\%) were successfully medically managed with anti-inflammatory and analgesic drugs plus exercise restriction; however, 10 (32\%) failed medical treatment and subsequently underwent surgical decompression, and 3 $(10 \%)$ were euthanized due to progression of their clinical signs. $^{73}$

Repeated epidural infiltration of methylprednisolone has recently gained favor after an initial report of reduced clinical signs in 30/38 dogs (79\%), with 20 dogs considered by their owners to be free of signs at a median followup of 48 months. ${ }^{8}$ A median of five epidural injections was required and the study specifically excluded cases with neurologic deficits. In anecdotal experience with Police GSDs (AW), epidural corticosteroids are often initially effective at reducing low back pain and keeping them in work, but most operational dogs will relapse. Repeated treatment with epidural corticosteroids is therefore reasonably effective for working dogs close to retirement and can lengthen their career. But for younger working dogs that must continue to perform a strenuous physical role, surgical management is thought to be more effective (AW) although more data are required to support this contention.

There may be a significant role for muscle conditioning and strengthening of the core muscles that support the lower back and LS junction. The use of physical rehabilitation should be a part of the conservative management of dogs with DLSS, but as with other recommendations, there is a paucity of objective outcome measures on which to base a treatment recommendation.

There are two contrasting strategies when surgery is employed for the management of DLSS: decompression 
of the L7 or sacral/caudal nerve roots versus distraction/ stabilization of the LS junction. ${ }^{74}$ The decompressive surgical technique that is most widely reported for the management of DLSS involves partial dorsal laminectomy of L7 and the sacrum, with a dorsal annulectomy of the prolapsed L7-S1 annulus fibrosus. ${ }^{1,4,26,75,76}$ Other studies have used dorsal decompression without annulectomy, or dorsal decompression with disc fenestration and partial discectomy of L7-S1. ${ }^{77,78}$ Suwankong et al (2008) reported poorer results in dogs that had partial discectomy concurrent to dorsal laminectomy compared to dorsal laminectomy alone, questioning its validity. ${ }^{5}$ It appears advisable to avoid discectomy or fenestration of the L7 disc because it is likely to lead to collapse of the disc space and exacerbate foraminal stenosis. ${ }^{79}$ Dorsal laminectomy can only provide limited access to the L7-S1 lateral intervertebral neurovascular foramen (at the entrance zone), which may result in continued clinical signs in dogs when narrowing is sited at the middle or exit zones. ${ }^{3}$ The lateral intervertebral neurovascular foramen can be enlarged by extending the dorsal laminectomy beneath the L7 articular process, a "facetectomy", or approaching the exit zone of the foramen dorsolaterally. ${ }^{1,3,72}$ Facetectomy is the complete removal of the L7 caudal articular process and is not recommended without concurrent stabilisation as this procedure may induce instability of the LS junction or fracture of the

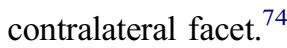

The lateral foraminotomy technique described by Godde and Steffen (2007) decompresses the entry, middle and exit zones of the L7-S1 neurovascular foramen by removing bone from the caudal pedicle of L7 directly over the lateral recess working rostrally from the foramen. ${ }^{3}$ The surgical approach required for this procedure is technically challenging and haemorrhage around the L7 nerve root, especially when encountered during an endoscopically assisted procedure, may be difficult to control, and results in fibrosis with potential residual root pain. A partial or complete cranial osteotomy of the ilial wing has been reported as providing a truly lateral exposure for an L7-S1 foraminotomy. ${ }^{80,81}$ The outcome of lateral foraminotomy was reported as good to excellent in 19 of the 20 dogs at a mean follow-up of 15.2 months using owner evaluation. ${ }^{3}$ In a recent longer-term evaluation of lateral foraminotomy for canine DLSS - 33/34 owners stated their dogs achieved complete resolution of clinical signs and they considered their dog to be clinically normal at a mean follow-up of 22.9 months. ${ }^{82}$
The alternative approach to dorsal or lateral decompression of the LS junction is to provide surgical stabilization to prevent its motion. The simplest method is to use a transilial bar to prevent excessive dorsiflexion (which narrows the intervertebral foramina). ${ }^{83}$ Although associated with good results in the initial report, there have been no further study reports; a possible late-term complication is the loss of bone on the spinous process leading to loss of effectiveness. Slocum and Devine (1986) advanced the principle of permanently stabilizing the LS junction in "normal alignment" (angle not defined). ${ }^{84}$ The technique involved fixation of the L7-S1 process articulation with trans-articular pins. After a standard dorsal approach, the dorsal interarcuate space is distracted with a laminectomy spreader until the rostrocaudal alignment of the articular processes is subjectively "normal" then bone pins are inserted across the L7-S1 articulation on each side into the sacrum. A bone graft, usually procured from an ilial wing, is added to encourage dorsal fusion. A modification is to use screws instead of pins and attempt to debride cartilage from the articular facets prior to grafting. ${ }^{85}$ If a significant dorsal laminectomy of the caudal aspect of L7 is performed concurrent to screw/pin fixation there may be weakening of the articular processes, which may lead to fracture of an articular process. ${ }^{86}$ Some surgeons, therefore, limit dorsal laminectomy to only the cranial aspect of $\mathrm{S} 1,{ }^{87}$ preserving bone stock for trans-articular fixation, or do not perform a laminectomy in conjunction with fixation as originally described by Slocum and Devine (1980). ${ }^{84}$ Bending, loosening and fracture of screws have all been observed. ${ }^{88-90}$ Transarticular facet screw stabilization and dorsal laminectomy has been reported to achieve satisfactory clinical outcome $^{89}$ but is associated with significant implant failure and does not consistently result in rigid stabilization. ${ }^{90}$ Clinical outcome is reportedly similar to dorsal decompression alone, Table 1. To make the construct stiffer and stronger and avoid implant failure multiple pins or screws can be placed in L7 and S1 then bonded into a dorsal construct with bone cement whilst maintaining the LS junction at a neutral LS angle. ${ }^{91}$ Pedicle screw-rod fixation, commonly used for posterior fusion in humans, is now being trialed in dogs using either the USS Small Stature System (DePuy Synthes, Amersfoort, The Netherlands) or the "string of pearls" (SOP, Orthomed, Huddersfield, UK) locking plate. ${ }^{92-94}$ Pedicle screw fixation, where the implants are placed vertically to engage the L7 pedicle avoids loading of the articular processes, which affords a more aggressive dorsal or dorsomedial decompression and 


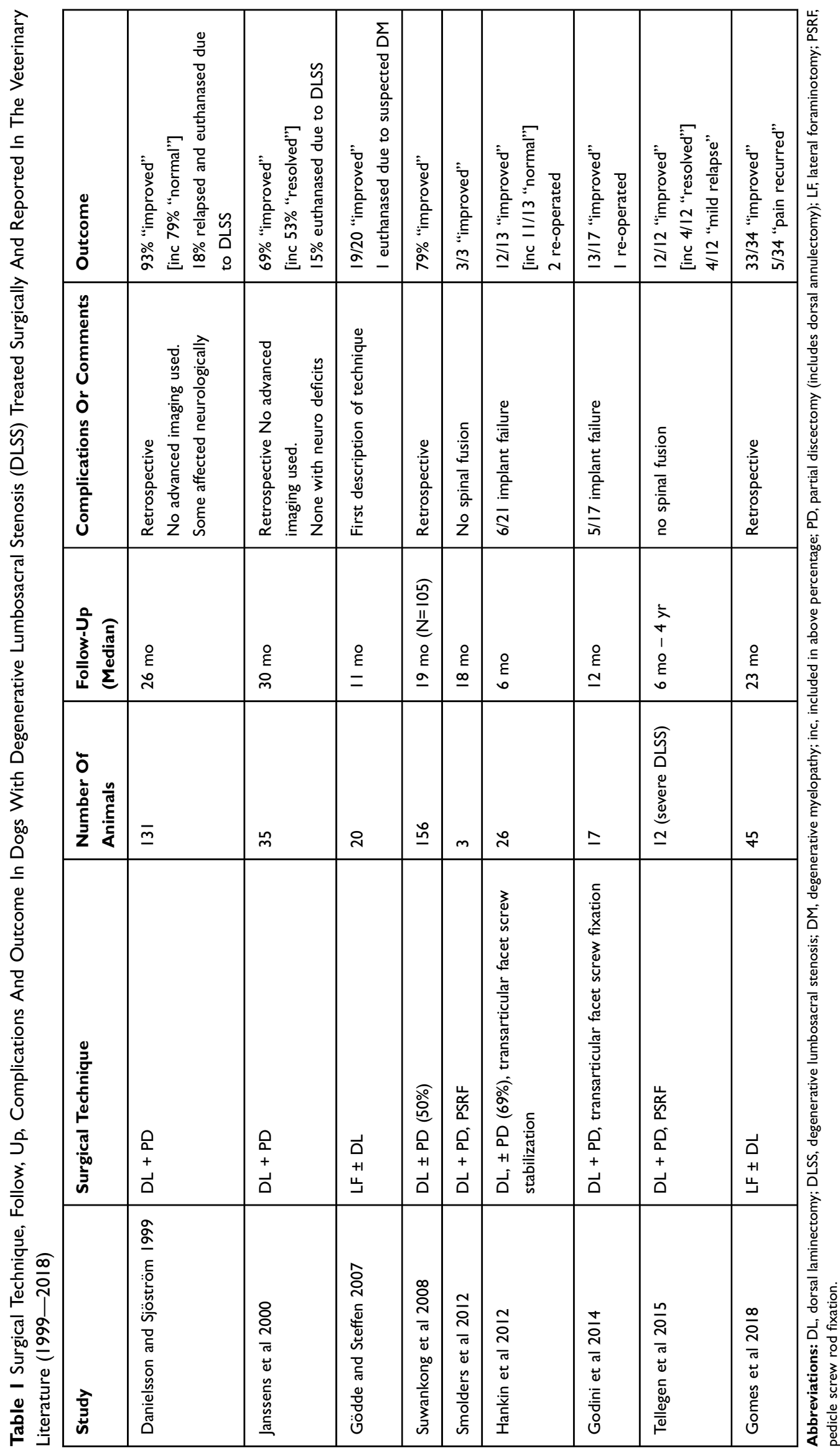


decreases any concern over articular process fracture. ${ }^{92,93}$ However, the authors have experienced screw failure when using SOP implants at the LS junction and do not recommend their use in dogs over $25 \mathrm{~kg}$.

Specialized medical devices are generally manufactured for human use and may not be an appropriate size for a small animal patient. Additionally, they are expensive and have not been widely reported in veterinary surgery for these reasons. However, in the last 5 years, vertebral implants are being developed for the veterinary market on a small scale like the Canine Vertebral Screw and Rod Fixation System (Orthopeasia, Bangkok, Thailand), ${ }^{95}$ and the Arcas Polyaxial pedicle screws \& rods (Artemedics, Minneapolis, MN, USA). A novel spinal implant using dumbbell-shaped connecting rods in a polyaxial coupling system has been described for LS fixation in dogs but these implants are not commercially available at the time of writing. ${ }^{96,97}$ One challenge facing developers of rigid stabilization-fusion systems for the LS junction in dogs is the welldescribed phenomenon of adjacent disc space degeneration following spinal fusion in humans. The adjacent intervertebral discs are subjected to greater motion as the result of the LS junction being rigidly stabilized. ${ }^{90}$

The authors have been investigating the utility of pedicle screw-rod fixation alone, ${ }^{95,98}$ or together with intervertebral spacers like SynCage (DePuy Synthes), ${ }^{99}$ (BM) or patientspecific 3D-printed titanium implants (AW) with promising results.

\section{Summary}

Degenerative lumbosacral stenosis is described as a clinical syndrome associated with degenerative changes to the LS junction that are acquired and typically occur in large breed and active dogs. There may be breed-associated morphological or biological characteristics and activity-related factors that when combined lead to premature degeneration of the L7-S1 IVD. The L7-S1 intervertebral disc loses its normal

\section{Clinical Signs Consistent with DLSS (ddx ruled out)}

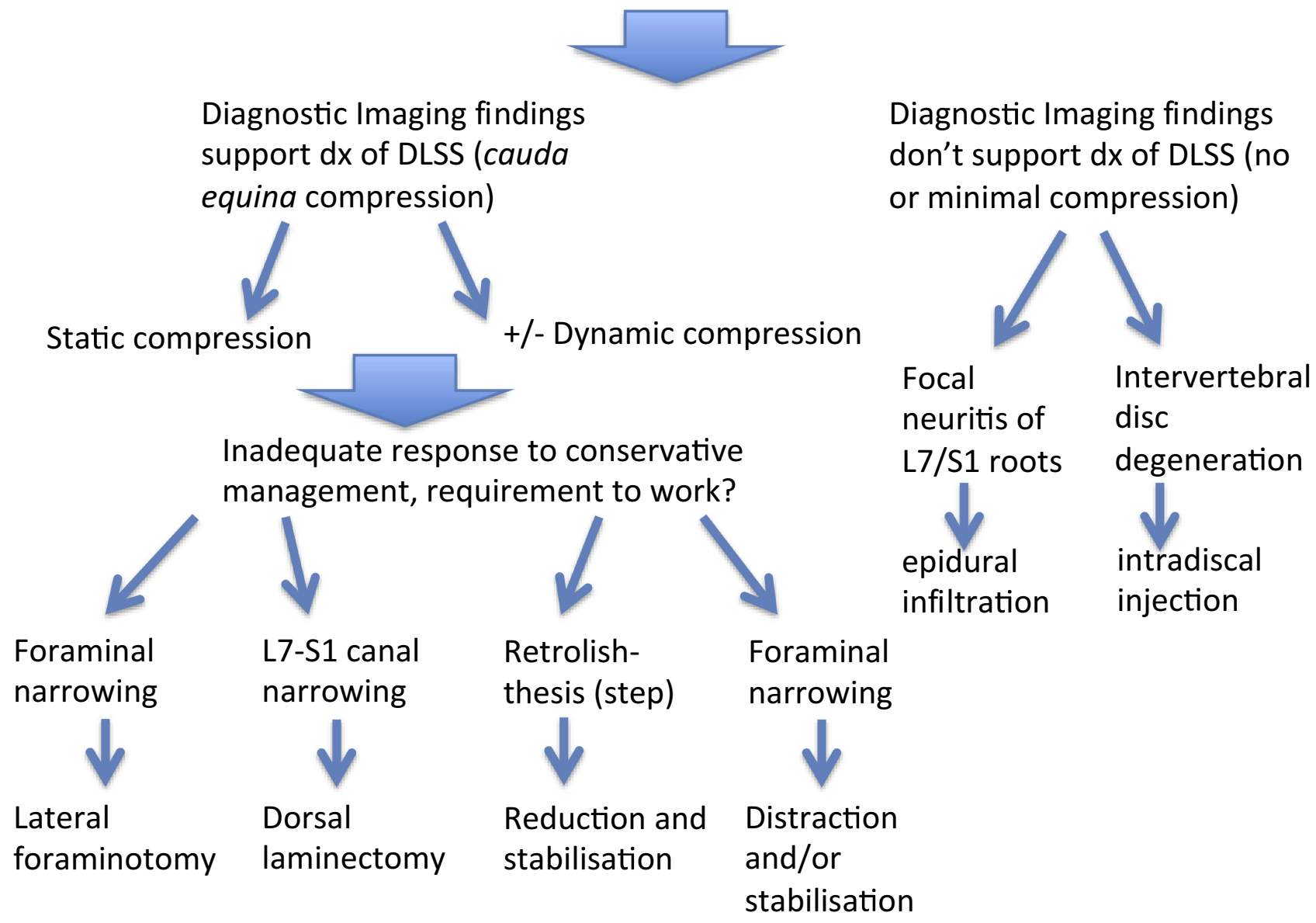

Figure 2 Suggested treatment algorithm for the management of degenerative lumbosacral stenosis in dogs pending a more evidence-based approach. 
biomechanical properties and the resulting degenerative changes in the supporting soft tissue and bony structures of the LS junction contribute to the characteristic compression of the L7, sacral and caudal nerve roots. Dynamic alteration of the dimensions of the L7-S1 lateral intervertebral neurovascular foramina (related to extension) is thought to lead to repeated compression of the neurovascular bundles exiting the foramina. Ideally carefully selected cohorts of individuals with DLSS would be randomly assigned to treatment groups to compare specific therapies and determine if, on average, any are superior. Due to the current lack of high-quality evidence on which to base treatment recommendations, we recommend that dogs with DLSS are initially managed conservatively, and that this should include core strengthening exercises. In dogs that fail conservative management (and potentially young working dogs), a careful consideration of the benefits of surgery is appropriate. In dogs without pelvic limb neurological signs or without evidence of L7 root lesions and/or foraminal stenosis on imaging, decompressive dorsal laminectomy may prove effective. In dogs with pelvic limb neurological signs or evidence of L7 root lesions and/or foraminal stenosis on imaging, foraminotomy or distraction/stabilization should be considered. New developments on spinal injections for early degeneration and lumbosacral implants for late degeneration increase the treatment arsenal for the veterinary surgeon that will be better equipped to tailor the treatment strategy to stratified categories of dogs with DLSS and low back pain. Figure 2 is a suggested treatment algorithm until a more evidence-based approach can be conceived.

\section{Disclosure}

Dr Andrew Worth reports grants from Massey University Working Dog Centre, during the conduct of the study. The authors declare no other conflicts of interest in this work.

\section{References}

1. Chambers J. Degenerative lumbosacral stenosis in dogs. Vet Med Rep. 1989;1:166-180.

2. *DeRisio L, Thomas W, Sharp N. Degenerative lumbosacral stenosis. Vet Clin North Am. 2000;30:130-133.

3. Gödde T, Steffen F. Surgical treatment of lumbosacral foraminal stenosis using a lateral approach in twenty dogs with degenerative lumbosacral stenosis. Vet Surg. 2007;36:705-713. doi:10.1111/j.1532950X.2007.00324.X

4. Danielsson F, Sjöström L. Surgical treatment of degenerative lumbosacral stenosis in dogs. Vet Surg. 1999;28:91-98.

5. Suwankong N, Meij BP, Voorhout G, de Boer AH, Hazewinkel HAW. Review and retrospective analysis of degenerative lumbosacral stenosis in 156 dogs treated by dorsal laminectomy. Vet Comp Orthop Traumatol. 2008;21:285-293.
6. Moore GE, Burkman KD, Carter MN, Peterson MR. Causes of death or reasons for euthanasia in military working dogs: 927 cases (1993-1996). $J$ Am Vet Med Assoc. 2001;219:209-214. doi:10.2460/javma.2001.219.209

7. Jeffery ND, Barker A, Harcourt-Brown T. What progress has been made in the understanding and treatment of degenerative lumbosacral stenosis in dogs during the past 30 years? Vet J. 2014;201:9-14. doi:10.1016/j.tvj1.2014.04.018

8. Janssens LA, Beosier YM, Daems R. Lumbosacral degenerative stenosis in the dog: the results of epidural infiltration with methylprednisolone acetate: a retrospective study. Vet Comp Orthop Traumatol. 2009;22:486-491. doi:10.3415/VCOT-08-07-0055

9. Willems N, Mihov G, Grinwis GC, et al. Safety of intradiscal injection and biocompatibility of polyester amide microspheres in a canine model predisposed to intervertebral disc degeneration. $J$ Biomed Mater Res $B$ Appl Biomater. 2017;105(4):707-714. doi:10.1002/jbm.b.33579

10. Tellegen AR, Willems N, Beukers M, et al. Intradiscal application of a PCLA-PEG-PCLA hydrogel loaded with celecoxib for the treatment of back pain in canines: what's in it for humans? $J$ Tissue End Regen M. 2017;12(3):642-652. doi:10.1002/term.2483

11. Tellegen AR, Rudnik-Jansen I, Beukers M, et al. Intradiscal delivery of celecoxib-loaded microspheres restores intervertebral disc integrity in a preclinical canine model. J Control Release. 2018;286:439-450. doi:10.1016/j.jconrel.2018.08.019

12. Demoulin C, Distree V, Tomasella M, Crielaard JM, Vanderthommen M. Lumbar functional instability: a critical appraisal of the literature. Ann Réadapt Méd Phys. 2007;50:10-16. doi:10.1016/j.annrmp.2007.05.007

13. *Dupuis P. The Natural History of Degenerative Changes in the Lumbar Spine. Rockville (MD, USA): Aspen Publishers; 1987.

14. Steffen F, Hunold K, Scharf G, Roos M, Fluckiger M. A follow-up study of neurologic and radiographic findings in working German Shepherd Dogs with and without degenerative lumbosacral stenosis. $J$ Am Vet Med Assoc. 2007;231(10):1529-1533. doi:10.2460/javma.231.10.1529

15. Hansen T, Smolders LA, Tryfonidou MA, et al. The myth of fibroid degeneration in the canine intervertebral disc: a histopathological comparison of intervertebral disc degeneration in chondrodystrophic and nonchondro-dystrophic dogs. Vet Pathol. 2017;54:945-952. doi: $10.1177 / 0300985817726834$

16. Bray JP, Burbidge HM. The canine intervertebral disk - Part two: degenerative changes - Nonchondrodystrophoid versus chondrodystrophoid disks. J Am Anim Hosp Assoc. 1998;34:135-144. doi:10.5326/1547331734-2-135

17. Wood BC, Lanz OI, Jones JC, Shires PK. Endoscopic-assisted lumbosacral foraminotomy in the dog. Vet Surg. 2004;33:221-231. doi:10.1111/j.1532-950X.2004.04033.x

18. Axlund TW, Hudson JA. Computed tomography of the normal lumbosacral intervertebral disc in 22 dogs. Vet Radiol Ultrasound. 2003;44:630-634. doi:10.1111/j.1740-8261.2003.tb00521.x

19. Worth AJ, Hartman A, Bridges JP, Jones BR, Mayhew IG. Computed tomographic evaluation of dynamic alteration of the canine lumbosacral intervertebral neurovascular foramina. Vet Surg. 2017;46 (2):255-264. doi:10.1111/vsu.12599

20. Mathews KA. Neuropathic pain in dogs and cats: if only they could tell us if they hurt. Vet Clin North Am Small Anim Pract. 2008;38:1365-1414. doi:10.1016/j.cvsm.2008.09.001

21. Matiasek K, Steffen F, Gödde T. Entrapped L7 dorsal root ganglia show an increased expression of calcium channel subunit alpha-2-delta (Poster Presentation). Selected research communications of the 23rd Symposium of the ESVN-ECVN Cambridge. J Vet Int Med. 2011;26(1):218-219.

22. Kobayashi S, Kokubo Y, Uchida K, et al. Effect of lumbar nerve root compression on primary sensory neurons and their central branches Changes in the nociceptive neuropeptides substance $\mathrm{P}$ and somatostatin. Spine. 2005;30(3):276-282. doi:10.1097/01.brs.0000152377.72468.f4

23. Kobayashi S, Sasaki S, Shimada S, et al. Changes of calcitonin generelated peptide in primary sensory neurons and their central branch after nerve root compression of the dog. Arch Phys Med Rehabil. 2005;86(3):527-533. doi:10.1016/j.apmr.2004.03.037 
24. Patel R, Dickenson AH. Mechanisms of the gabapentinoids and $\alpha 2$ $\delta$-1 calcium channel subunit in neuropathic pain.Pharmacol Res Perspect. 2016;4(2):e00205. doi:10.1002/prp2.205

25. Willems N, Tellegen AR, Bergknut $\mathrm{N}$, et al. Inflammatory profiles in canine intervertebral disc degeneration. BMC Vet Res. 2016;12:10. doi:10.1186/s12917-016-0635-6

26. Ness M. Degenerative lumbosacral stenosis in the dog: a review of 30 cases. J Small Anim Pract. 1994;35:185-190. doi:10.1111/j.17485827.1994.tb01683.x

27. DeRisio L, Sharp N, Olby N, Munana K, Thomas W. Predictors of outcome after dorsal decompressive laminectomy for degenerative lumbosacral stenosis in dogs: 69 cases (1987-97). J Am Vet Med Assoc. 2001;219:624-628. doi:10.2460/javma.2001.219.624

28. Bergknut N, Egenvall A, Hagman R, et al. Incidence of intervertebral disk degeneration-related diseases and associated mortality rates in dogs. J Am Vet Med Assoc. 2012;240:1300-1309. doi:10.2460/ javma.240.11.1300

29. Worth AJ, Sandford SM, Gibson IB, Stratton R, Erceg V, Jones B. Causes of loss from active duty for New Zealand Police German Shepherd Dogs. J Anim Welfare. 2013;22(2):167-174.

30. Lang J, Hani H, Schawalder P. A sacral lesion resembling osteochondrosis in the German shepherd dog. Vet Radiol Ultrasound. 1992;33:69-76. doi:10.1111/j.1740-8261.1992.tb01962.x

31. Hanna FY. Lumbosacral osteochondrosis: radiological features and surgical management in 34 dogs. J Small Anim Pract. 2001;42:271-278.

32. Mathis KR, Havlicek M, Beck JB, Eaton-Wells RD, Park FM. Sacral osteochondrosis in two German shepherd dogs. Aust Vet J. 2009;87:249-252. doi:10.1111/j.1751-0813.2009.00418.x

33. Ondeka N, Amort KH, Stock KF, et al. Skeletal morphology of the lumbosacral junction in German shepherd dogs and an evaluation of the possible genetic basis for radiographic findings. Vet J. 2013;196:64-70. doi:10.1016/j.tvj1.2012.07.015

34. Worth AJ. Custom titanium implants for stabilisation of the canine lumbosacral joint. Abstract. Veterinary Orthopedic Society, Big Sky, Montana, Feb 28- Mar 3, 2016. Vet Comp Orthop Traumatol. 2016;29 (3):A28.

35. Wigger A, Julier-Franz C, Tellhelm B, Kramer M. Lumbosacral transitional vertebrae in the German shepherd dog: prevalence, classification, genetics, and association with canine hip dysplasia. Tierärztliche Praxis Ausgabe Kleintiere Heimtiere. 2009;37:7-13.

36. Morgan JP, Bahr A, Franti CE, Bailey CS. Lumbosacral transitional vertebrae as a predisposing cause of cauda-equina syndrome in German-Shepherd dogs - 161 cases (1987-1990). J Am Vet Med Assoc. 1993;202:1877-1882.

37. Scharf G, Steffen F, Gruenenfelder FI, Morgan JP, Fluckiger M. The lumbosacral junction in working German shepherd dogs - neurological and radiological evaluation. $J$ Vet Med. 2004;51:27-32. doi:10.1111/j.1439-0442.2004.00587.x

38. Damur-Djuric N, Steffen F, Hassig M, Morgan JP, Fluckiger MA. Lumbosacral transitional vertebrae in dogs: classification, prevalence, and association with sacroiliac morphology. Vet Radiol Ultrasound. 2006;47:32-38. doi:10.1111/j.1740-8261.2005.00102.x

39. Fluckiger MA, Damur-Djuric N, Hassig M, Morgan JP, Steffen F. A lumbosacral transitional vertebra in the dog predisposes to cauda equina syndrome. Vet Radiol Ultrasound. 2006;47:39-44. doi:10.1111/j.1740-8261.2005.00103.x

40. Meij BP, Bergknut N. Degenerative lumbosacral stenosis in dogs. Vet Clin Small Anim. 2010;20:983-1009. doi:10.1016/j.cvsm.2010.05.006

41. Suwankong N, Voorhout G, Hazewinkel HAW, Meij BP. Agreement between computed tomography, magnetic resonance imaging, and surgical findings in dogs with degenerative lumbosacral stenosis. J Am Vet Med Assoc. 2006;229:1924-1929. doi:10.2460/javma.229.12.1924

42. Schmid V, Lang J. Measurements on the lumbosacral junction in normal dogs and those with cauda-equina compression. J Small Anim Pract. 1993;34:437-442. doi:10.1111/j.1748-5827.1993.tb03897.x
43. Mattoon JS, Koblik PD. Quantitative survey radiographic evaluation of the lumbosacral spine of normal dogs and dogs with degenerative lumbosacral stenosis. Vet Radiol Ultrasound. 1993;34:194-206. doi:10.1111/j.1740-8261.1993.tb02005.x

44. Blume LM, Worth AJ, Cohen EB, Bridges JP, Hartman AC. Accuracy of radiographic detection of the cranial margin of the dorsal lamina of the canine sacrum. Vet Radiol Ultrasound. 2015;56(6):579588. doi:10.1111/vru. 12282

45. Saunders H, Worth AJ, Bridges JP, Hartman A. Evaluation of the rostral projection of the sacral lamina as a component of degenerative lumbosacral stenosis in German shepherd dogs. Vet Surg. 2018;47 (5):654-663. doi:10.1111/vsu.12899

46. Linn LL, Bartels KE, Rochat MC, Payton ME, Moore GE. Lumbosacral stenosis in 29 military working dogs: epidemiologic findings and outcome after surgical intervention (1990-1999). Vet Surg. 2003;32:21-29. doi:10.1053/jvet.2003.50001

47. Jones JC, Davies SE, Werre SR, Shackelford KL. Effects of body position and clinical signs on L7-S1 intervertebral foraminal area and lumbosacral angle in dogs with lumbosacral disease as measured via computed tomography. Am J Vet Res. 2008;69:1446-1454. doi:10.2460/ajvr.69.11.1446

48. Morgan JP, Bailey CS. Cauda equina syndrome in the dog: radiographic evaluation. J Small Anim Pract. 1990;31:69-77. doi:10.1111/ j.1748-5827.1990.tb00724.x

49. De Decker S, Gregori T, Kenny PJ, Hoy C, Erles K, Volk HA. Tethered cord syndrome associated with a thickened filum terminale in a dog. Vet Int Med. 2015;29:405-409. doi:10.1111/jvim.12522

50. De Decker S, Watts V, Neilson DM. Dynamic lumbosacral magnetic resonance imaging in a dog with tethered cord syndrome with a tight filum terminale. Front Vet Sci. 2017;18:134. doi:10.3389/fvets.2017.00134

51. Meij BP, Voorhout G, Wolvekamp WT. Epidural lipomatosis in a six-yearold dachshund. Vet Rec. 1996;138:492-495. doi:10.1136/vr.138.20.492

52. De Nies KS, Edwards RA, Bergknut N, Beukers M, Meij BP. Caudal lumbar spinal cysts in two French Bulldogs. Acta Vet Scand. 2018;60:14. doi:10.1186/s13028-018-0368-6

53. Sulla I, Balik V, Hornak S, Ledecky V. Cauda equina syndrome in dogs - a review. Acta Veterinaria Brno. 2018;87:321-330. doi:10.2754/avb201887040321

54. Palmer RH, Chambers JN. Canine lumbosacral diseases. Part 1. Anatomy, pathophysiology and clinical presentation. Compend Contin Educ Pract Vet. 1991;13:61-68.

55. Worth AJ, Thompson DJ, Hartman AC. Degenerative lumbosacral stenosis in working dogs: current concepts and review. $N Z$ Vet J. 2009;57(6):319-330. doi:10.1080/00480169.2009.64719

56. Hathcock JT. Vacuum phenomenon of the canine spine - CT findings in 3 patients. Vet Radiol Ultrasound. 1994;35:285-289. doi:10.1111/ j.1740-8261.1994.tb02043.x

57. Schwarz T, Owen MR, Long S, Sullivan M. Vacuum disk and facet phenomenon in a dog with cauda equina syndrome. J Am Vet Med Assoc. 2000;217:862-864. doi:10.2460/javma.2000.217.862

58. Ramirez O, Thrall DE. A review of imaging techniques for canine cauda equina syndrome. Vet Radiol Ultrasound. 1998;39:283-296. doi:10.1111/j.1740-8261.1998.tb01608.x

59. Jones JC, Cartee RE, Bartels JE. Computed tomographic anatomy of the canine lumbosacral spine. Vet Radiol Ultrasound. 1995;36:91-99. doi:10.1111/j.1740-8261.1995.tb00223.x

60. Henninger W, Werner G. CT examination of the canine lumbosacral spine in extension and flexion. Part 1: bone window. Eur $J$ Companion Anim Pract. 2003;13:215-226.

61. Henninger W, Werner G. CT examination of the canine lumbosacral spine in extension and flexion. Part 2: soft-tissue window. Eur $J$ Companion Anim Pract. 2003;13:227-233.

62. Jones JC, Inzana KD. Subclinical CT abnormalities in the lumbosacral spine of older large-breed dogs. Vet Radiol Ultrasound. 2000;41:19-26. doi:10.1111/j.1740-8261.2000.tb00421.x 
63. Gordon S, Bridges JP, Tomiln SC, Hartman A, Worth AJ. Repeatability of three-dimensional computed tomographic volumetric measurement of lumbosacral intervertebral foramina in German shepherd dogs. Vet Comp Orthop Traumatol. 2018;31(5):339-343. doi:10.1055/s-0038-1660873

64. Karkkainen M, Punto LU, Tulamo RM. Magnetic-resonance-imaging of canine degenerative spinal diseases. Vet Radiol Ultrasound. 1993;34:399-404. doi:10.1111/j.1740-8261.1993.tb02028.x

65. Adams WH, Daniel GB, Pardo AD, Selcer RS. Magnetic-resonanceimaging of the caudal lumbar and lumbosacral spine in 13 dogs (1990-1993). Vet Radiol Ultrasound. 1995;36:3-13. doi:10.1111/ j.1740-8261.1995.tb00204.x

66. Mayhew PD, Kapatkin AS, Wortman JA, Vite CH. Association of cauda equina compression on magnetic resonance images and clinical signs in dogs with degenerative lumbosacral stenosis. J Am Anim Hosp Assoc. 2002;38:555-562. doi:10.5326/0380555

67. Da Costa RC, Samii VF. Advanced imaging of the spine in small animals. Vet Clin North Am Small Anim Pract. 2010;40:765-790. doi:10.1016/j.cvsm.2010.05.002

68. Jones JC, Banfield CM, Ward DL. Association between postoperative outcome and results of magnetic resonance imaging and computed tomography in working dogs with degenerative lumbosacral stenosis. $\mathrm{J} \mathrm{Am} \mathrm{Vet}$ Med Assoc. 2000;216:1769-1774. doi:10.2460/javma.2000.216.1769

69. Sisson AF, LeCouteur RA, Ingram JT, Park RD, Child G. Diagnosis of cauda equina abnormalities by using electromyography, discography, and epidurography in dogs. J Vet Int Med. 1992;6:253-263. doi:10.1111/j.1939-1676.1992.tb00349.x

70. Meij BP, Suwankong N, Van Den Brom WE, Van Haagen AJV, Hazewinkel HAW. Tibial nerve somatosensory evoked potentials in dogs with degenerative lumbosacral stenosis. Vet Surg. 2006;35:168175. doi:10.1111/j.1532-950X.2006.00128.x

71. Harcourt-Brown TR, Granger NP, Fitzpatrick N, Jeffery ND. Electrodiagnostic findings in dogs with apparently painful lumbosacral foraminal stenosis. J Vet Int Med. 2019;33(5):2167-2174. doi: $10.1111 /$ jvim. 15589

72. Tarvin G, Prata RG. Lumbosacral stenosis in dogs. J Am Vet Med Assoc. 1980;177:154-159.

73. De Decker S, Wawrzenski LA, Volk HA. Clinical presentation and outcome for dogs treated medically for degenerative lumbosacral stenosis. J Vet Int Med. 2014;28:944-975.

74. Palmer RH, Chambers JN. Canine lumbosacral diseases. Part II. Definitive diagnosis, treatment, and prognosis. Compend Contin Educ Pract Vet. 1991;13:213-222.

75. Denny HR, Gibbs C, Holt PE. The diagnosis and treatment of cauda equina lesions in the dog. J Small Anim Pract. 1982;23:435-443. doi:10.1111/j.1748-5827.1982.tb03772.x

76. Janssens LAA, Moens Y, Coppens P, Peremans K, Vinck H. Lumbosacral degenerative stenosis in the dog. Vet Comp Orthop Traumatol. 2000;13:97-103. doi:10.1055/s-0038-1632638

77. Klaveren NJ, Suwankong N, De Boar S, et al. Force plate analysis before and after dorsal decompression for treatment of degenerative lumbosacral stenosis in dogs. Vet Surg. 2005;34:450-456. doi:10.1111/j.1532-950X.2005.00068.x

78. Suwankong N, Meij BP, Klaveren NJ, et al. Assessment of decompressive surgery in dogs with degenerative lumbosacral stenosis using force plate analysis and questionnaires. Vet Surg. 2007;36:423-431. doi:10.1111/j.1532-950X.2007.00288.x

79. Worth AJ, Hartman A, Bridges JP, Jones BR, Mayhew IG. Effect of dorsal laminectomy and dorsal annulectomy with partial lumbosacral discectomy on the volume of the lateral intervertebral neuroforamina in dogs when the lumbosacral junction is extended. Vet Surg. 2017;46 (2):265-270. doi:10.1111/vsu.12606

80. Saulnier-Troff FG, De Busscher V, Motta L Proceedings of the 17th ESVOT Congress; 2014; 363-364. Venice.

81. Dyall B, Schmoekel H. Complete cranial iliac osteotomy to approach the lumbosacral foramen. Front Vet Sci. 2017;4:75. doi:10.3389/ fvets.2017.00075
82. Gomes SA, Lowrie M, Targett M. Long-term outcome following lateral foraminotomy as treatment for canine degenerative lumbosacral stenosis. Vet Rec. 2018;183(11):352-356. doi:10.1136/ vr.104741

83. Müller F, Schenk HC, Forterre F. Short-term and long-term effects of a minimally invasive transilial vertebral blocking procedure on the lumbosacral morphometry in dogs measured by computed tomography. Vet Surg. 2017;46(3):354-366. doi:10.1111/vsu.12623

84. Slocum B, Devine T. L7-S1 fixation-fusion for treatment of cauda equina compression in the dog. J Am Vet Med Assoc. 1986;188:31-35.

85. *Bagley RS. Surgical stabilisation of the lumbosacral joint. In: Slatter DH, editor. Textbook of Small Animal Surgery. 3rd ed. Philadelphia (USA): Saunders; 2003:1238-1243.

86. Moens N, Runyon C. Fracture of L7 vertebral articular facets and pedicles following dorsal laminectomy in a dog. $\mathrm{J} \mathrm{Am} \mathrm{Vet} \mathrm{Med} \mathrm{Assoc.}$ 2002;221:807-810. doi:10.2460/javma.2002.221.807

87. Kinsel S, Koch J, Stopinski. Cauda equina compression syndrome: retrospective study of surgical treatment with partial laminectomy in 86 dogs with lumbosacral stenosis. Berl Munch Tierartzl Wuchenshr. 2004; 117:334-340.

88. *Sharp NJH, Wheeler SJ. Lumbosacral Disease. Small Animal Spinal Disorders. Philadelphia (USA): Elsevier Mosby; 2005:181-209.

89. Hankin EJ, Jerram RM, Walker AM, King MD, Warman CGA. Transarticular facet screw stabilization and dorsal laminectomy in 26 dogs with degenerative lumbosacral stenosis with instability. Vet Surg. 2012;41:611-619. doi:10.1111/j.1532-950X.2012.01002.x

90. Golini L, Kircher PR, Lewis FI, Steffen F. Transarticular fixation with cortical screws combined with dorsal laminectomy and partial discectomy as surgical treatment of degenerative lumbosacral stenosis in 17 dogs: clinical and computed tomography follow-up. Vet Surg. 2014;43(4):405-413. doi:10.1111/j.1532-950X.2014.12117.x

91. *Beam R, Powers D, Hauptman J, Sanders S. Dynamic lumbosacral instability; clinical evaluation and owner perceived outcome of a novel approach for surgical distraction-stabilisation of L7-S1: 51 cases (20082013). J Vet Int Med. 2014;28:1016. doi:10.1111/jvim.12284

92. Meheust P, Mallet C, Marouze C. A new surgical technique for lumbosacral stabilisation: arthrodesis using pedicle screw fixation. Anatomical aspects. Pratique Médicale Et Chirurgicale De L'Animal De Compaignie. 2000;35:193-199.

93. Meij BP, Suwankong N, Van Der Veen AJ, Hazewinkel HAW. Biomechanical flexion-extension forces in normal canine lumbosacral cadaver specimens before and after dorsal laminectomy-discectomy and pedicle screw-rod fixation. Vet Surg. 2007;36:742-751. doi:10.1111/j.1532-950X.2007.00331.x

94. Smolders LA, Voorhout G, van de Ven R, et al. Pedicle screw-rod fixation of the canine lumbosacral junction. Vet Surg. 2012;41:720732. doi:10.1111/j.1532-950X.2012.00989.x

95. Lewchalermwong P, Suwanna N, Meij BP. Canine vertebral screw and rod fixation system: design and mechanical testing. Vet Comp Orthop Traumatol. 2018;31(2):95-101. doi:10.3415/VCOT-17-03-0040

96. Fitzpatrick N Degenerative lumbosacral stenosis: intervertebral spacer and screw-rod fixation system for distraction-fusion. Proceedings of the 4th World Veterinary Orthopaedic Congress; March 1-8, 2014; 137-138. Colorado: Breckenridge.

97. Zindl C, Litsky AS, Fitzpatrick N, Allen MJ. Kinematic behavior of a novel pedicle screw-rod fixation system for the canine lumbosacral joint. Vet Surg. 2018;47:114-124. doi:10.1111/vsu.12742

98. Tellegen AR, Willems N, Tryfonidou MA, Meij BP. Pedicle screwrod fixation: a feasible treatment for dogs with severe degenerative lumbosacral stenosis. BMC Vet Res. 2015;11:299. doi:10.1186/ s12917-015-0614-3

99. Teunissen M, van der Veen AJ, Smit TH, Tryfonidou MA, Meij BP. Effect of a titanium cage as a stand-alone device on biomechanical stability in the lumbosacral spine of canine cadavers. Vet $J$. 2017;220:17-23. doi:10.1016/j.tvj1.2016.12.007 


\section{Publish your work in this journal}

Veterinary Medicine: Research and Reports is an international, peerreviewed, open access journal publishing original research, case reports, editorials, reviews and commentaries on all areas of veterinary medicine. The manuscript management system is completely online

and includes a very quick and fair peer-review system. Visit http://www.dovepress.com/testimonials.php to read real quotes from published authors.

Submit your manuscript here: http://www.dovepress.com/veterinary-medicine-research-and-reports-journal 